\title{
Recovery Support for Internet-based Real-Time Collaborative Editing Systems
}

\author{
Xiao Qin and Chengzheng Sun \\ School of Computing and Information Technology \\ Griffith University \\ Brisbane, Queensland 4111, Australia \\ \{xqin,C.Sun\}@cit.gu.edu.au
}

\begin{abstract}
For reliability, recovery support must be employed in the Internet-based real-time collaborative editing systems. This paper describes a recovery scheme in which each site maintains a local document state (LDS) that is generated periodically. Thus, if a failure occurs in the Internet links or at the site, the site can rejoin the collaborative editing system by loading the LDS instead of obtaining the state from the remote sites. This is a much faster process than the traditional approach the recovery of regaining the system's document state from other peer sites. Consistency between the local state and remote state during the recovery procedure is maintained in a recovery algorithm for which the proof is provided. The performance of our recovery scheme is assessed by generating the elapsed time between a failed site joining and leaving the systems.
\end{abstract}

\section{Introduction}

Using real-time collaborative editing systems, groups of geographically distributed users can view and edit simultaneously shared documents. Real-time collaborative editing systems are important groupware applications [3][14][19][21][23]. It is important for these systems to have a good responsiveness, support of unconstrained collaboration, and are tolerant of failed processes. A real-time collaborative editor system on the Internet must tolerate site and link failures [16]. Two main fault tolerant techniques are replication [6][13] and persistence [17]. With replication, the hardware and software components replicated process the same messages in the same order. If any one fails, others are still able to continue. Persistence-based solutions rely on checkpointing whereby during the normal execution, application states are periodically saved on a stable storage and used during the recovery to rollback to an earlier consistent state.

Traditionally, recovery of a failed site has been implemented by regaining the system's document state from other peer sites. However, the recovery latency can be significantly long if the volume of data associated with the document state is large. Substantial delays can be reduced if recovery does not start from scratch. A failed site can rejoin the collaborative editing system without starting from the very beginning if an efficient approach is used.

We investigated an approach in which each site maintains a LDS that is generated periodically. Thus, if a failure occurs in the Internet links or at the site, the site can rejoin the collaborative editing system by loading the LDS instead of obtaining the state from the remote sites, a much faster process. During the recovery procedure, the consistency between the local state and remote state is maintained in a recovery algorithm.

The rest of the paper is organized as follows. In Section 2, we present the system model. Fault-tolerant algorithms and the proof of the correctness are given in section 3. The performance analysis of the algorithm is presented in section 4. Section 5 outlines the related work, and section 6 summarizes the contributions of this paper and suggests future directions of our research.

\section{System Model}

The Internet-based real-time collaborative editing system is modeled by a pair CES $=\langle\mathrm{S}, \mathrm{C}\rangle$. S is a finite set of sites $S=\left\{s_{1}, s_{2}, \ldots, s_{n}\right\}$, where $s_{i}$ is a site involved in editing work. $\mathrm{C}$ is a finite set of channels, $\mathrm{C}=\left\{\mathrm{c}_{\mathrm{ij}}, 1 \leq\right.$ $\mathrm{i} \leq \mathrm{n}, \mathrm{i}<\mathrm{j} \leq \mathrm{n}\}$, where $\mathrm{c}_{\mathrm{ij}}$ is a point-to-point channels that connect site $s_{i}$ and $s_{j}$ via the Internet. $s_{i}^{\prime} s$ execution is a sequence of operations which includes the remote operations from other sites. $\mathrm{LDS}_{\mathrm{i}}$ is the LDS that is generated periodically and stored on permanent storage, when the site $\mathrm{s}_{\mathrm{i}}$ failed, $\mathrm{LDS}_{\mathrm{i}}$ will be used to initialize the site.

Definition 1. Given an operation $\mathrm{O}$, then $\mathrm{s}(\mathrm{O})$ denotes the site at which $\mathrm{O}$ is generated, $\mathrm{e}_{\mathrm{i}}(\mathrm{O})$ represents the execution form of $\mathrm{O}$ at $\mathrm{s}_{\mathrm{i}}, \mathrm{gt}_{\mathrm{i}}(\mathrm{O})$ denotes the time when $\mathrm{s}_{\mathrm{i}}$ generates $\mathrm{O}$, and $\mathrm{at}_{\mathrm{i}}(\mathrm{O})$ represents the execution time of $\mathrm{O}$ at the remote sites $\mathrm{s}_{\mathrm{i}}$. It is certain that $\mathrm{gt}_{\mathrm{i}}(\mathrm{O}) \rightarrow \mathrm{s}(\mathrm{O})=\mathrm{i}$, and $\mathrm{at}_{\mathrm{i}}(\mathrm{O}) \rightarrow \mathrm{s}(\mathrm{O}) \neq \mathrm{i}$.

Definition 2. Given two operations $\mathrm{O}_{\mathrm{i}}$ and $\mathrm{O}_{\mathrm{j}}, \mathrm{O}_{\mathrm{i}}$ is causal order preceding $\mathrm{O}_{\mathrm{j}}$, denoted by $\mathrm{O}_{\mathrm{i}} \rightarrow \mathrm{O}_{\mathrm{j}}$, iff: 
(1) $\mathrm{s}\left(\mathrm{O}_{\mathrm{i}}\right)=\mathrm{s}\left(\mathrm{O}_{\mathrm{j}}\right)=\mathrm{k}$, and $\mathrm{gt}_{\mathrm{k}}\left(\mathrm{O}_{\mathrm{i}}\right)<\mathrm{gt}_{\mathrm{k}}\left(\mathrm{O}_{\mathrm{j}}\right)$;

(2) $\mathrm{s}\left(\mathrm{O}_{\mathrm{i}}\right) \neq \mathrm{s}\left(\mathrm{O}_{\mathrm{j}}\right)$, at $_{\mathrm{k}}\left(\mathrm{O}_{\mathrm{i}}\right)<\mathrm{gt}_{\mathrm{k}}\left(\mathrm{O}_{\mathrm{j}}\right)$, where $\mathrm{k}=\mathrm{s}\left(\mathrm{O}_{\mathrm{j}}\right)$;

(3)There exists an operation $\mathrm{O}_{\mathrm{k}}$, such that $\mathrm{O}_{\mathrm{i}} \rightarrow \mathrm{O}_{\mathrm{k}}, \mathrm{O}_{\mathrm{k}} \rightarrow \mathrm{O}_{\mathrm{j}}$.

Definition 3. Operation $\mathrm{O}_{i}$ and $\mathrm{O}_{j}$ are independent if and only if neither $\mathrm{O}_{\mathrm{i}} \rightarrow \mathrm{O}_{\mathrm{j}}$, nor $\mathrm{O}_{\mathrm{j}} \rightarrow \mathrm{O}_{\mathrm{i}}$, which is defined as $\mathrm{O}_{\mathrm{i}} \| \mathrm{O}_{\mathrm{j}}$.

Definition 4. An operation is associated with a context, denoted as $\mathrm{CT}_{\mathrm{O}}$, which is the list of operations that need to be executed to bring the document from its initial states to the states on which $\mathrm{O}$ is defined.

Definition 5. Given two operations $\mathrm{O}_{\mathrm{i}}$ and $\mathrm{O}_{\mathrm{j}}$, associated with contexts $\mathrm{CT}_{\mathrm{Oi}}$ and $\mathrm{CT}_{\mathrm{Oj}}, \mathrm{O}_{\mathrm{i}}$ and $\mathrm{O}_{\mathrm{j}}$ are context equivalent, i.e., $\mathrm{O}_{\mathrm{i}} \sqcup \mathrm{O}_{\mathrm{j}}$, if only iff, $\mathrm{CT}_{\mathrm{Oi}}=\mathrm{CT}_{\mathrm{Oj}}$.

Definition 6. Given two operations $\mathrm{O}_{i}$ and $\mathrm{O}_{j}$, associated with contexts $\mathrm{CT}_{\mathrm{Oi}}$ and $\mathrm{CT}_{\mathrm{Oj}}, \mathrm{O}_{\mathrm{i}}$ is context preceding $\mathrm{O}_{\mathrm{j}}$, i.e., $\mathrm{O}_{\mathrm{i}} \succ \mathrm{O}_{\mathrm{j}}$, if only if, $\mathrm{CT}_{\mathrm{Oj}}=\mathrm{CT}_{\mathrm{Oi}}+\left[\mathrm{O}_{\mathrm{j}}\right]$.

Definition 7. Given two operations $\mathrm{O}_{\mathrm{i}}$ and $\mathrm{O}_{\mathrm{j}}, \mathrm{s}\left(\mathrm{O}_{\mathrm{i}}\right)=\mathrm{a}$, $\mathrm{s}\left(\mathrm{O}_{\mathrm{j}}\right)=\mathrm{b}$, and timestamped by $\mathrm{SV}_{\mathrm{Oi}}$ and $\mathrm{SV}_{\mathrm{Oj}}$, respectively [21], then $\mathrm{O}_{i}$ is total order preceding $\mathrm{O}_{j}$, i.e., $\mathrm{O}_{\mathrm{i}} \Rightarrow \mathrm{O}_{\mathrm{j}}$, iff (1) $\operatorname{sum}\left(\mathrm{SV}_{\mathrm{Oi}}\right)<\operatorname{sum}\left(\mathrm{SV}_{\mathrm{Oj}}\right)$ or $(2) \mathrm{a}<\mathrm{b}$ when $\operatorname{sum}\left(\mathrm{SV}_{\mathrm{Oi}}\right)=\operatorname{sum}\left(\mathrm{SV}_{\mathrm{Oi}}\right)$, where $\operatorname{sum}(\mathrm{SV})=\sum_{i=1}^{n} S V[i]$.

Definition 8. Let $\mathrm{HB}_{\mathrm{i}}{ }^{\mathrm{t}}$ be the history buffer of $\mathrm{s}_{\mathrm{i}}$ at time $\mathrm{t}$. In $\mathrm{HB}_{\mathrm{i}}{ }^{\mathrm{t}}, \mathrm{y}_{\mathrm{i}}{ }^{\mathrm{j}, \mathrm{t}}$ denotes the latest operation generated at site $\mathrm{s}_{\mathrm{j}}$, iff, $\forall \mathrm{O} \in \mathrm{HB}_{\mathrm{i}}^{\mathrm{t}}, \mathrm{O} \neq \mathrm{y}_{\mathrm{i}}^{\mathrm{j}, \mathrm{t}}: \mathrm{s}(\mathrm{O})=\mathrm{j} \rightarrow\left(\mathrm{O} \rightarrow \mathrm{y}_{\mathrm{i}}^{\mathrm{j}, \mathrm{t}}\right)$.

Each site $s_{i}$ maintains a status $\xi_{i}$ that is one of the following: join, run, checkpoint, recovery, fail and finish. The recovery begins by loading the LDS from the local permanent storage. If no LDS is available, the state is initialized to join and remains in this state until it receives the Remote Document state (RDS) from the other sites and executes operations according to the RDS. On the other hand, if the site has a LDS then setting up the site depends on the state in LDS. If the state in LDS is finish, it means this site exited successfully during the last session. Then, the state changes from finish into join and the site obtains the RDS from other sites, the state changes from join into run after the site execute operations associated with RDS. If the state in LDS is run, it means that this site did not exit successfully due to the link failure or site failure. So, the state changes into recover followed by loading all the data in LDS. After finish obtaining LDS and receiving all missed operations entered at its own site, the state is set to run. The user's interface is not enabled until the state of the site is run. This case is described formally by theorem 2 .

If the current state is join, the site propagates a join message to all other sites, then wait for the first remote site that reply this message. After receiving the document state from this remote site and the site is initialized, the state of the site changes into run. If it does not receive any reply, it assumes that it is the first one to join the system. In this case, the local document is loaded and the state is updated into run. If the state is checkpoint, it stores LDS on the local permanent storage, and changes the state to run. In case that the state is finish, it saves LDS, followed by broadcasting a finish message to other sites.

In most cases, the site is in run state. The site waits for operations and processes according to each operation received. If the operation is the local finish operation, the state is changed from run into finish. If the operation is other kinds of local operations, the site executes the operation, appends the operation into its history buffer and broadcast it to other sites. If the operation is a remote operation generated at other sites, it is transformed before being executed [21]. The state diagram is described in Figure 1.

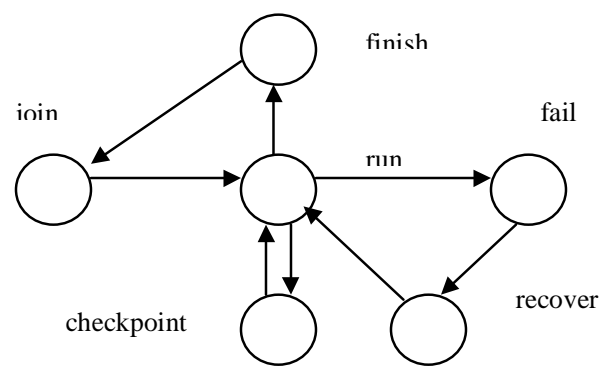

Figure1. Diagram state for sites

There are two different architectures for storing shared documents: centralized and replicated. Though centralized approach is simple, it results in the poor responsiveness, especially in the Internet environment. Replicated approach, however, exhibits a better responsive time, since each site can update the local document immediately followed by propagate to the remote sites. In replicated architecture, concurrency control to maintain consistency in replicated document is one of several essential issues. To solve the inconsistency problems, the consistency model was given in paper [21].

\section{Recovery Algorithm}

Before presenting the recovery algorithm, a algorithm to decide the latest operation generated at site $s_{j}$ in $\mathrm{Hb}_{\mathrm{i}}{ }^{\mathrm{t}}$ is described as follows.

Algorithm 1. $\mathrm{LO}\left(\mathrm{HB}_{\mathrm{i}}{ }_{\mathrm{t}}, \mathrm{j}\right)$ : Given a history buffer $\mathrm{HB}_{\mathrm{i}}{ }^{\mathrm{t}}$ at site $\mathrm{s}_{\mathrm{i}}, \mathrm{y}_{\mathrm{i}}^{\mathrm{j}}$ is the latest operation generated at $\mathrm{s}_{\mathrm{j}}$; and is obtained as the follows,

$$
\begin{aligned}
& \mathrm{j} \leftarrow\left|\mathrm{HB}_{\mathrm{i}}^{\mathrm{t}}\right| \text {; } \\
& \text { while }(\mathrm{j}>0) \text { do } \\
& \quad \mathrm{O} \leftarrow \mathrm{HB}_{\mathrm{i}}^{\mathrm{t}}[\mathrm{j}] \text {; } \\
& \quad \text { if } \mathrm{s}(\mathrm{O})=\mathrm{j} \text { then return } \mathrm{y}_{\mathrm{i}}^{\mathrm{j}}=\mathrm{O} \text {; } \\
& \quad \text { else } \mathrm{j} \leftarrow \mathrm{j}-1 \text {; } \\
& \text { end while } \\
& \text { return } \varphi \text {; }
\end{aligned}
$$

end algorithm 1.

The following three lemmas describe the features of 
two operations generated at the same site.

Lemma 1. Given two operations $\mathrm{O}_{\mathrm{i}}$ and $\mathrm{O}_{\mathrm{j}}$ : if $\mathrm{s}\left(\mathrm{O}_{\mathrm{i}}\right)=$ $\mathrm{s}\left(\mathrm{O}_{\mathrm{j}}\right)$ then either $\mathrm{O}_{\mathrm{i}} \rightarrow \mathrm{O}_{\mathrm{j}}$ or $\mathrm{O}_{\mathrm{j}} \rightarrow \mathrm{O}_{\mathrm{i}}$.

Proof. Given $s\left(\mathrm{O}_{\mathrm{i}}\right)=\mathrm{s}\left(\mathrm{O}_{\mathrm{j}}\right)$ : if the generation of $\mathrm{O}_{\mathrm{i}}$ happened before the generation of $\mathrm{O}_{j}$ then $\mathrm{O}_{\mathrm{i}} \rightarrow \mathrm{O}_{\mathrm{j}}$ (see Definition.2) else the generation of $\mathrm{O}_{\mathrm{j}}$ happened before the generation of $\mathrm{O}_{\mathrm{I}}$ and $\mathrm{O}_{\mathrm{j}} \rightarrow \mathrm{O}_{\mathrm{i}}$.

Lemma 2. Given two operations $\mathrm{O}_{\mathrm{i}}$ and $\mathrm{O}_{\mathrm{j}}$ : if $\mathrm{O}_{\mathrm{i}}$ is causal order preceding $\mathrm{O}_{\mathrm{j}}$ then $\mathrm{O}_{\mathrm{i}}$ is total order preceding $\mathrm{O}_{\mathrm{j}}$ and $\forall \mathrm{O}_{\mathrm{i}}, \mathrm{O}_{\mathrm{i}}:\left(\mathrm{s}\left(\mathrm{O}_{\mathrm{i}}\right) \rightarrow \mathrm{s}\left(\mathrm{O}_{\mathrm{j}}\right)\right) \rightarrow\left(\mathrm{O}_{\mathrm{i}} \Rightarrow \mathrm{O}_{\mathrm{j}}\right)$.

Proof given in [20].

Lemma 3. Given two operations $\mathrm{O}_{i}$ and $\mathrm{O}_{\mathrm{j}}$ in the history buffer HB: if two operations are generated at the same site and $\mathrm{O}_{\mathrm{i}}$ is total order preceding to $\mathrm{O}_{j}$, then $\mathrm{O}_{\mathrm{i}}$ is causal order preceding $\mathrm{O}_{\mathrm{j}}$ and $\forall \mathrm{O}_{\mathrm{i}}, \mathrm{O}_{\mathrm{j}} \in \mathrm{HB}$ : $\left(\mathrm{s}\left(\mathrm{O}_{\mathrm{i}}\right)=\mathrm{s}\left(\mathrm{O}_{\mathrm{j}}\right) \wedge \mathrm{O}\right.$ $\left.\mathrm{i}_{\mathrm{i}} \rightarrow \mathrm{O}_{\mathrm{j}}\right) \rightarrow\left(\mathrm{O}_{\mathrm{i}} \rightarrow \mathrm{O}_{\mathrm{j}}\right)$.

Proof. If lemma 3 is incorrect, then either $\mathrm{O}_{j} \rightarrow \mathrm{O}_{i}$ or $\mathrm{O}_{\mathrm{i}} \|$ $\mathrm{O}_{\mathrm{j}}$. Because $\mathrm{s}\left(\mathrm{O}_{\mathrm{i}}\right)=\mathrm{s}\left(\mathrm{O}_{\mathrm{j}}\right)$, only $\mathrm{O}_{\mathrm{j}} \rightarrow \mathrm{O}_{\mathrm{i}}$ (lemma 1) is possible and thus $\mathrm{O}_{\mathrm{j}} \Rightarrow \mathrm{O}_{\mathrm{i}}$ (lemma 2) which is a contradiction.

Given $\mathrm{HB}_{\mathrm{i}}{ }^{\mathrm{t}}$ and $\mathrm{s}_{\mathrm{j}}$, algorithm 1 determine the latest operation generated at $\mathrm{s}_{\mathrm{j}}$, we prove the correctness of the algorithm 1. in the following theorem.

Theorem 1. Given $\mathrm{HB}_{\mathrm{i}}{ }^{\mathrm{t}}$ and site $\mathrm{s}_{\mathrm{j}}$, the operation $\mathrm{O}$ to be determined by algorithm $\mathrm{LO}\left(\mathrm{HB}_{\mathrm{i}}{ }_{\mathrm{i}}^{\mathrm{t}}, \mathrm{j}\right)$ is $\mathrm{y}_{\mathrm{i}}^{\mathrm{j}}$.

Proof. Since algorithm $\mathrm{YO}\left(\mathrm{HB}_{\mathrm{i}}{ }_{\mathrm{t}}, \mathrm{j}\right)$ scans the history buffer $\mathrm{HB}_{\mathrm{i}}^{\mathrm{t}}$ from right to left, we have $\forall \mathrm{O}_{\mathrm{k}} \in \mathrm{HB}_{\mathrm{i}}{ }^{\mathrm{t}}, \mathrm{O}_{\mathrm{k}}=$ $\mathrm{HB}_{\mathrm{i}}^{\mathrm{t}}[\mathrm{a}], \mathrm{O}=\mathrm{HB}_{\mathrm{i}}^{\mathrm{t}}[\mathrm{b}], \mathrm{O}_{\mathrm{k}} \neq \mathrm{O}: \mathrm{s}\left(\mathrm{O}_{\mathrm{k}}\right)=\mathrm{s}(\mathrm{O})=\mathrm{j} \rightarrow \mathrm{a}<\mathrm{b}$. Thus, $\mathrm{O}_{\mathrm{k}} \Rightarrow \mathrm{O}$ is proved, so $\mathrm{O}_{\mathrm{k}} \rightarrow \mathrm{O}$ (lemma 3). Hence, $\forall$ $\mathrm{O}_{\mathrm{k}} \in \mathrm{HB}_{\mathrm{i}}{ }^{\mathrm{t}}, \mathrm{O}_{\mathrm{k}} \neq \mathrm{O}: \mathrm{s}\left(\mathrm{O}_{\mathrm{k}}\right)=\mathrm{j} \rightarrow\left(\mathrm{O}_{\mathrm{k}} \rightarrow \mathrm{O}\right)$, so $\mathrm{O}=\mathrm{y}_{\mathrm{i}}^{\mathrm{j}, \mathrm{t}}$ (Def. 8).

If a link or site fails, the site is allowed to rejoin the system without starting from scratch. In our recovery approach, we reduce the state transmission delay by loading the system's state from the local permanent storage instead of the remote site. If the site is in recovery status, the site rejoins by loading the LDS and propagating a recovery message $r$, then wait for reply from other sites. Algorithm 2 outlines the procedure for a failed site rejoining the system by loading the LDS.

\section{Algorithm 2.}

Let $\mathrm{HB}_{\mathrm{i}}{ }^{\mathrm{t}}$ be the history buffer associated with the latest checkpoint, that generated at time $t$.

Local operation generation is disabled;

$\mathrm{y}_{\mathrm{i}}^{\mathrm{i}, \mathrm{t}} \leftarrow \mathrm{LO}\left(\mathrm{HB}_{\mathrm{i}}^{\mathrm{t}}, \mathrm{i}\right)$;

for $1 \leq \mathrm{i} \leq \mathrm{n}$ where $\mathrm{i} \neq \mathrm{j}$ do

$\mathrm{y}_{\mathrm{i}}^{\mathrm{j}, \mathrm{t}} \leftarrow \mathrm{LO}\left(\mathrm{HB}_{\mathrm{i}}^{\mathrm{t}}, \mathrm{j}\right)$;

put $\mathrm{y}_{\mathrm{i}}^{\mathrm{i}, \mathrm{t}}$ and $\mathrm{y}_{\mathrm{i}}^{\mathrm{j}, \mathrm{t}}$ into the recovery message;

send the recovery message to site $\mathrm{s}_{\mathrm{j}}$;

end for;

while true do

Waiting for the operations sent from peer sites:

if $\mathrm{O}$ is the operation which satisfied: $\mathrm{SV}_{\mathrm{O}}[\mathrm{s}(\mathrm{O})] \leftarrow \mathrm{SV}_{\mathrm{i}}[\mathrm{s}(\mathrm{O})]+1$ and

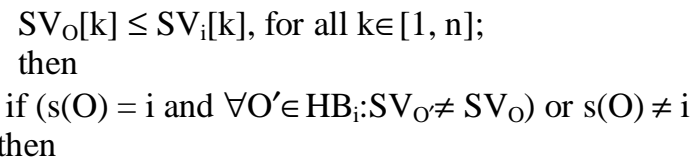

use Undo/Transform-Do/Transform-Redo [21] scheme to execute $\mathrm{O}$;

end if;

satisfied;

else $\mathrm{O}$ is delayed until two conditions are

if (all missed operations generated at $\mathrm{s}_{\mathrm{i}}$ has been executed at $\mathrm{s}_{\mathrm{i}}$ again)

then Local operation generation is enabled;

end while;

end algorithm 2 .

In this paper, we assume that at time $\theta$ when site $\mathrm{s}_{\mathrm{i}}$ has failed, $\mathrm{s}_{\mathrm{i}}$ generates the latest checkpoint at time $\sigma$, and begins the recovery procedure by loading checkpoint and transmits the recovery message $r$ at time $\gamma$.

It is crucial for the restored site to decide when it can start generating the operations again. In fact, the failed site $\mathrm{s}$ can begin operations only if it has received all lost operations generated at $s_{i}$ between $\sigma$ and $\theta$ from other sites. To prove the correctness of this point, we introduce theorem 2, and prove it. Before giving theorem 2, we present the property of time stamp and lemma 4.

Property 1. Let $\mathrm{O}$ be an operation generated at s. $\mathrm{O}$ is time-stamped by $\mathrm{SV}_{\mathrm{O}}$. After executing $\mathrm{O}$ at $\mathrm{s}, \mathrm{SV}_{\mathrm{O}}[\mathrm{s}]=$ $\mathrm{SV}[\mathrm{s}]+1$, where $\mathrm{SV}$ is the current local state vector.

Lemma 4. Given two operations $\mathrm{O}$ and $\mathrm{O}^{\prime}$ generated at the same site $s_{i}$, the ith sector in their time stamp are different, thus, $\forall \mathrm{O}, \mathrm{O}^{\prime}, 1 \leq \mathrm{i} \leq \mathrm{n}: \mathrm{s}(\mathrm{O})=\mathrm{s}\left(\mathrm{O}^{\prime}\right)=\mathrm{i}, \mathrm{O} \neq \mathrm{O}^{\prime}$ $\rightarrow \mathrm{SV}_{\mathrm{O}}[\mathrm{i}] \neq \mathrm{SV}_{\mathrm{O}^{\prime}}[\mathrm{i}]$.

Proof. Because $\mathrm{s}(\mathrm{O})=\mathrm{s}\left(\mathrm{O}^{\prime}\right)=\mathrm{i}$, either $\mathrm{O} \rightarrow \mathrm{O}^{\prime}$ or $\mathrm{O}^{\prime} \rightarrow \mathrm{O}$ (lemma 1). Assume $\mathrm{O} \rightarrow \mathrm{O}^{\prime}$ and that between $\mathrm{O}$ and $\mathrm{O}^{\prime}$, $\mathrm{s}_{\mathrm{i}}$ generates other $\mathrm{k}-1(\mathrm{k}>0)$ operations, thus $\mathrm{O} \rightarrow \mathrm{O}_{\mathrm{k}-1} \rightarrow$ $\ldots \rightarrow \mathrm{O}_{2} \rightarrow \mathrm{O}_{1} \rightarrow \mathrm{O}^{\prime}$, then $\mathrm{SV}_{\mathrm{O}}[\mathrm{i}]=\mathrm{SV}_{\mathrm{Ok}-1}[\mathrm{i}]+1=\mathrm{SV}_{\mathrm{Ok}-}$ ${ }_{2}[\mathrm{i}]+2=\ldots=\mathrm{SV}_{\mathrm{O}}$, [i] $+\mathrm{k}$, where $\mathrm{k}>0$ (Property 1 ). Hence, we prove that $\mathrm{SV}_{\mathrm{O}}[\mathrm{i}] \neq \mathrm{SV}_{\mathrm{O}^{\prime}}[\mathrm{i}]$. We use the same way to prove lemma 4 when $\mathrm{O}^{\prime} \rightarrow \mathrm{O}$.

Theorem 2. Let $\sigma, \theta$ and $\gamma$ be the latest checkpoint time, rash time and recovery time at $s_{i}$. $s_{i}$ can only generate operations after time $\mathrm{t}(\mathrm{t}>\gamma)$, when all operations generated at $\mathrm{s}_{\mathrm{i}}$ between $\sigma<\mathrm{gt}_{\mathrm{i}}(\mathrm{O})<\theta$ execute at the $\mathrm{s}_{\mathrm{i}}$ again, that is, $\forall \mathrm{O}: \sigma<\mathrm{gt}_{\mathrm{i}}(\mathrm{O})<\theta \rightarrow \mathrm{e}_{\mathrm{i}}(\mathrm{O}) \in \mathrm{HB}_{\mathrm{i}}^{\mathrm{t}}$.

Proof. Suppose theorem 2 is incorrect, then $s_{i}$ generates an operations $\mathrm{O}_{\mathrm{s}}$ at time $\mathrm{t}^{\prime}>\gamma$, when at least one operation generated at $\mathrm{s}_{\mathrm{i}}$ between $\sigma<\mathrm{gt}_{\mathrm{i}}(\mathrm{O})<\theta$ does not execute at the $\mathrm{s}_{\mathrm{i}}$ again. Thus, $\exists \mathrm{O}: \sigma<\mathrm{gt}_{\mathrm{i}}(\mathrm{O})<\theta \rightarrow \mathrm{e}_{\mathrm{i}}(\mathrm{O}) \notin \mathrm{HB}_{\mathrm{i}}{ }^{\mathrm{t}^{\prime}}$. Let $\mathrm{O}_{1} \rightarrow \mathrm{O}_{2} \rightarrow \ldots \rightarrow \mathrm{O}_{\mathrm{k}}$ be $\mathrm{k}(\mathrm{k}>0)$ operations generated at $\mathrm{s}_{\mathrm{i}}$ between $\sigma<\mathrm{gt}_{\mathrm{i}}(\mathrm{O})<\theta$, so we have $\forall 1 \leq \mathrm{j} \leq \mathrm{h}$ : $\mathrm{e}_{\mathrm{i}}(\mathrm{O}) \in$ $\mathrm{HB}_{\mathrm{i}} \mathrm{t}^{\mathrm{t}^{\prime}}$. and $\forall \mathrm{h}+1 \leq \mathrm{j} \leq \mathrm{ke}_{\mathrm{i}}(\mathrm{O}) \notin \mathrm{HB}_{\mathrm{i}} \mathrm{t}^{\prime}$. Assume that when $\mathrm{s}_{\mathrm{i}}$ generates the latest checkpoint at time $\sigma$, the local state vector is $\mathrm{SV}[\mathrm{i}]=\mathrm{d}$, then after executing $\mathrm{O}_{\mathrm{h}}$ on $\mathrm{s}_{\mathrm{i}}$ again, 
$\mathrm{SV}$ [i] becomes $\mathrm{d}+\mathrm{h}$. So, the operation $\mathrm{SV}_{\mathrm{Os}}[\mathrm{i}]=\mathrm{d}+\mathrm{h}+$ 1. The timestamp of the operation $\mathrm{O}_{\mathrm{h}+1}$ that has not executed at $s_{i}$ again is: $\mathrm{SV}_{\mathrm{Oh}+1}[\mathrm{i}]=\mathrm{d}+\mathrm{h}+1$. So we proved that $\mathrm{SV}_{\mathrm{Os}}[\mathrm{i}]=\mathrm{SV}_{\mathrm{Oh}+1}[\mathrm{i}]$. Since $\mathrm{O}_{\mathrm{s}} \neq \mathrm{O}_{\mathrm{h}+1}, \mathrm{SV}_{\mathrm{Os}}[\mathrm{i}]$ $\neq \mathrm{SV}_{\mathrm{Oh}+1}$ [i] (lemma 4), this is a contradiction. So theorem 2 is correct.

If after time $\sigma$, there is at least one operation from other site is executed at $\mathrm{s}_{\mathrm{i}}$, or $\mathrm{s}_{\mathrm{i}}$ generates at least one, then the saved local state is inconsistent with remote state at other sites. This feature is presented in theorem 3. Before proving theorem 3 , we address five properties of history buffer as follows:

Property 2. If the generation time of $\mathrm{O}$ at $\mathrm{s}_{\mathrm{i}}$ is earlier than $\mathrm{t}$, then $\mathrm{e}_{\mathrm{i}}(\mathrm{O})$ is in the history buffer $\mathrm{HB}_{\mathrm{i}}{ }^{\mathrm{t}}$, thus, $\forall \mathrm{O}, 1 \leq \mathrm{i}$ $\leq \mathrm{n}: \mathrm{gt}_{\mathrm{i}}(\mathrm{O})<\mathrm{t} \rightarrow \mathrm{e}_{\mathrm{i}}(\mathrm{O}) \in \mathrm{HB}_{\mathrm{i}}^{\mathrm{t}}$.

Property 3. If the execution time of $\mathrm{O}(\mathrm{s}(\mathrm{O}) \neq \mathrm{i})$ at $s_{i}$ is earlier than $t$, then $\mathrm{e}_{\mathrm{i}}(\mathrm{O})$ is in the history buffer $\mathrm{HB}_{\mathrm{i}}{ }_{\mathrm{t}}^{\mathrm{t}}$, thus, $\forall \mathrm{O}, 1 \leq \mathrm{i} \leq \mathrm{n}: \mathrm{at}_{\mathrm{i}}(\mathrm{O})<\mathrm{t} \rightarrow \mathrm{e}_{\mathrm{i}}(\mathrm{O}) \in \mathrm{HB}_{\mathrm{i}}^{\mathrm{t}}$.

Property 4. If the generation time of $\mathrm{O}$ at $\mathrm{s}_{\mathrm{i}}$ is later than $\mathrm{t}$, then $\mathrm{e}_{\mathrm{i}}(\mathrm{O})$ is not in the history buffer $\mathrm{HB}_{\mathrm{i}}{ }^{\mathrm{t}}$, thus, $\forall \mathrm{O}, 1 \leq \mathrm{i}$ $\leq \mathrm{n}: \mathrm{gt}_{\mathrm{i}}(\mathrm{O})>\mathrm{t} \rightarrow \mathrm{e}_{\mathrm{i}}(\mathrm{O}) \notin \mathrm{HB}_{\mathrm{i}}{ }^{\mathrm{t}}$.

Property 5. If the execution time of $\mathrm{O}(\mathrm{s}(\mathrm{O}) \neq \mathrm{i})$ at $s_{i}$ is later than $\mathrm{t}$, then $\mathrm{e}_{\mathrm{i}}(\mathrm{O})$ is not in the history buffer $\mathrm{HB}_{\mathrm{i}}{ }^{\mathrm{t}}$, thus, $\forall \mathrm{O}, 1 \leq \mathrm{i} \leq \mathrm{n}: \mathrm{at}_{\mathrm{i}}(\mathrm{O})>\mathrm{t} \rightarrow \mathrm{e}_{\mathrm{i}}(\mathrm{O}) \notin \mathrm{HB}_{\mathrm{i}}^{\mathrm{t}}$.

Property 6. Let $\theta$ be the time when $\mathrm{s}_{\mathrm{i}}$ has failed, $\sigma$ be the time when $s_{i}$ generates the latest checkpoint and $\gamma$ be the time when $\mathrm{s}_{\mathrm{i}}$ begins its recovery procedure. For $\mathrm{s}_{\mathrm{i}}$, history buffer at time $\gamma$ is the same as that at time $\delta$, thus, $\mathrm{HB}_{\mathrm{i}}{ }^{\gamma}=$ $\mathrm{HB}_{\mathrm{i}}{ }^{\sigma}$.

Theorem 3. If after time $\sigma$, there is at least one operation from other site is executed at $\mathrm{s}_{\mathrm{i}}$, or $\mathrm{s}_{\mathrm{i}}$ generates at least one operation, $\mathrm{HB}_{\mathrm{i}}^{\gamma}$ does not equal to $\mathrm{HB}_{\mathrm{i}}{ }^{\theta}$. In other words, $\exists$ $\mathrm{O}:\left(\sigma<\mathrm{gt}_{\mathrm{i}}(\mathrm{O})<\theta \vee \sigma<\mathrm{at}_{\mathrm{i}}(\mathrm{O})<\theta\right) \rightarrow \mathrm{HB}_{\mathrm{i}}^{\gamma} \neq \mathrm{HB}_{\mathrm{i}}{ }^{\theta}$.

Proof. Firstly, suppose $O$ is the operation that satisfies $\sigma$ $<\mathrm{gt}_{\mathrm{i}}(\mathrm{O})<\theta$, we obtain that $\mathrm{e}_{\mathrm{i}}(\mathrm{O}) \in \mathrm{HB}_{\mathrm{i}}{ }^{\theta}$ (Property 2), and $\mathrm{e}_{\mathrm{i}}(\mathrm{O}) \notin \mathrm{HB}_{\mathrm{i}}{ }^{\sigma}$ (Property 4). So, we prove that $\mathrm{HB}_{\mathrm{i}}{ }^{\theta} \neq \mathrm{HB}_{\mathrm{i}}{ }^{\sigma}$. Since $\mathrm{HB}_{\mathrm{i}}^{\gamma}=\mathrm{HB}_{\mathrm{i}}{ }^{\sigma}$ (Property 6), $\mathrm{HB}_{\mathrm{i}}^{\gamma} \neq \mathrm{HB}_{\mathrm{i}}{ }^{\theta}$ is proved. Secondly, we suppose $\mathrm{O}$ is the operation that satisfies $\sigma$ $<\mathrm{at}_{\mathrm{i}}(\mathrm{O})<\theta$, and $\mathrm{s}(\mathrm{O})=\mathrm{j} \neq \mathrm{i}$, we have $\mathrm{e}_{\mathrm{i}}(\mathrm{O}) \in \mathrm{HB}_{\mathrm{i}}{ }^{\theta}$ (Property 2), and $\mathrm{e}_{\mathrm{i}}(\mathrm{O}) \notin \mathrm{HB}_{\mathrm{i}}{ }^{\sigma}$ (Property 5).So, we obtained $\mathrm{HB}_{\mathrm{i}}{ }^{\theta} \neq \mathrm{HB}_{\mathrm{i}}{ }^{\sigma}$. Because $\mathrm{HB}_{\mathrm{i}}^{\gamma}=\mathrm{HB}_{\mathrm{i}}{ }^{\sigma}$ (Property 6), $\mathrm{HB}_{\mathrm{i}}^{\gamma} \neq \mathrm{HB}_{\mathrm{i}}{ }^{\theta}$ is also proved. So Theorem 3 is correct.

Theorem 3 suggests that for all $\mathrm{O}$, which satisfy $\sigma<$ $\mathrm{gt}_{\mathrm{i}}(\mathrm{O})<\theta$ or $\sigma<\mathrm{at}_{\mathrm{i}}(\mathrm{O})<\theta$, are missing in $\mathrm{HB}_{\mathrm{i}}^{\gamma}$. If these operations are not reflected in $\mathrm{HB}_{\mathrm{i}}{ }^{\mathrm{t}}$, where $\mathrm{t}>\gamma, \mathrm{s}_{\mathrm{i}}$ is inconsistent with other sites. Therefore, consistency maintenance must be devised for the recovery procedure.

Assume that $\mathrm{y}_{\mathrm{i}}^{\mathrm{j}, \sigma}=\mathrm{e}_{\mathrm{i}}\left(\mathrm{O}_{\mathrm{k}}\right)$, we found that operations $\mathrm{O}$ generated at $s_{j},(1 \leq \mathrm{j} \leq \mathrm{n}, \mathrm{j} \neq \mathrm{i})$, where $\mathrm{gt}_{\mathrm{j}}\left(\mathrm{O}_{\mathrm{k}}\right)<\mathrm{gt}_{\mathrm{j}}(\mathrm{O})<$ at ${ }_{j}(r)$, are also missing in $\mathrm{HB}_{\mathrm{i}}^{\gamma}$. The purpose of the recovery algorithm is to find out all the lost operations in $\mathrm{s}_{\mathrm{i}}$ and the effect of their execution is remained unchanged. Hence, we introduce the consistency of the recovery as follows:

Definition 9. Let $\sigma, \theta$ and $\gamma$ be the latest checkpoint time, crash time and recovery time at $s_{i}$, the recovery is consistent: iff,

$\exists \mathrm{t}>\gamma: \forall \mathrm{O}:\left(\sigma<\mathrm{gt}_{\mathrm{i}}(\mathrm{O})<\theta \vee \mathrm{gt}_{\mathrm{j}}\left(\mathrm{O}_{\mathrm{k}}\right)<\mathrm{gt}_{\mathrm{j}}(\mathrm{O})<\mathrm{at}_{\mathrm{j}}(\mathrm{r})\right)$ $\rightarrow \mathrm{e}_{\mathrm{i}}(\mathrm{O}) \in \mathrm{HB}_{\mathrm{i}}{ }^{\mathrm{t}}$, where $\mathrm{y}_{\mathrm{i}}^{\mathrm{j}, \sigma}=\mathrm{e}_{\mathrm{i}}\left(\mathrm{O}_{\mathrm{k}}\right)$.

Let $s_{j}$ be the sites that receives the recovery message $r$ from site $s_{i},(i \neq j), s_{j}$ responds the message $r$ at time $t$. The algorithm is given below.

Algorithm 3. the algorithm in $s_{j}$ to respond the message $r$ Get $\mathrm{O}_{\mathrm{a}} \leftarrow \mathrm{y}_{\mathrm{i}}^{\mathrm{i}, \sigma}$ and $\mathrm{O}_{\mathrm{b}} \leftarrow \mathrm{y}_{\mathrm{i}}^{\mathrm{j}, \sigma}$ from the recovery message;

$\mathrm{k} \leftarrow 1 ; \mathrm{b}_{\mathrm{i}} \leftarrow$ false; $\mathrm{b}_{\mathrm{j}} \leftarrow$ false;

if $\mathrm{y}_{\mathrm{i}}^{\mathrm{i}, \sigma}=\varphi$ then $\mathrm{b}_{\mathrm{i}} \leftarrow$ ture;

if $\mathrm{y}_{\mathrm{i}}^{\mathrm{j}, \sigma}=\varphi$ then $\mathrm{b}_{\mathrm{j}} \leftarrow$ ture;

while $\mathrm{k} \leq\left|\mathrm{HB}_{\mathrm{j}}{ }^{\mathrm{t}}\right|$ do

$\mathrm{O} \leftarrow \mathrm{HB}_{\mathrm{j}}^{\mathrm{t}}[\mathrm{k}]$;

if ( $b_{i}=$ false) then if $\mathrm{SV}_{\mathrm{O}}=\mathrm{SV}_{\mathrm{Oa}}$ then $\mathrm{b}_{\mathrm{i}} \leftarrow$ true;

else if $\mathrm{s}(\mathrm{O})=\mathrm{i}$ then send $\mathrm{O}^{\prime} \leftarrow \operatorname{GORT}(\mathrm{O})$ to $\mathrm{s}_{\mathrm{i}}$;

if $\left(b_{j}=\right.$ false) then if $\mathrm{SV}_{\mathrm{O}}=\mathrm{SV}_{\mathrm{Ob}}$ then $\mathrm{b}_{\mathrm{j}} \leftarrow$ true;

else if $\mathrm{s}(\mathrm{O})=\mathrm{j}$ then send $\mathrm{O}^{\prime} \leftarrow \operatorname{GORT}(\mathrm{O})$ to $\mathrm{s}_{\mathrm{i}}$;

$\mathrm{k} \leftarrow \mathrm{k}+1$

end while;

end algorithm 3 .

Note that the operations, which need to be sent back to the rejoin site again, are sent in the original form when they are generated. In fact, the operations in the history buffer are in the execution form instead of the original form, so we devise algorithm GORT (algorithm 4) to obtain the original form of an operation in history buffer.

Let $\mathrm{HB}_{\mathrm{i}}{ }^{\mathrm{t}}$ be the history buffer of $\mathrm{s}_{\mathrm{i}}$ at time $\mathrm{t}, \mathrm{HB}_{\mathrm{i}}{ }^{\mathrm{t}}=$ $\left[\mathrm{e}_{\mathrm{i}}\left(\mathrm{O}_{1}\right), \mathrm{e}_{\mathrm{i}}\left(\mathrm{O}_{2}\right), \ldots, \mathrm{e}_{\mathrm{i}}\left(\mathrm{O}_{\mathrm{m}}\right)\right]$, and $\mathrm{e}_{\mathrm{i}}\left(\mathrm{O}_{\mathrm{j}}\right)$ is an operation in $\mathrm{HB}_{\mathrm{i}}^{\mathrm{t}}$.

In case that $\forall 1 \leq \mathrm{k} \leq \mathrm{j}-1: \mathrm{e}_{\mathrm{i}}\left(\mathrm{O}_{\mathrm{k}}\right) \rightarrow \mathrm{e}_{\mathrm{i}}\left(\mathrm{O}_{\mathrm{j}}\right)$, than original form of $\mathrm{O}_{\mathrm{j}}$ is the same as its execution form, thus, $\mathrm{O}_{\mathrm{j}}=$ $\mathrm{e}_{\mathrm{i}}\left(\mathrm{O}_{\mathrm{j}}\right)$.

Let $\mathrm{e}_{\mathrm{i}}\left(\mathrm{O}_{\mathrm{a}}\right)$ be the oldest operation that is independent of $\mathrm{e}_{\mathrm{i}}\left(\mathrm{O}_{\mathrm{j}}\right)$. In the simple case that $\forall 1 \leq \mathrm{k} \leq \mathrm{a}-1$ : $\mathrm{e}_{\mathrm{i}}\left(\mathrm{O}_{\mathrm{k}}\right) \rightarrow$ $\mathrm{e}_{\mathrm{i}}\left(\mathrm{O}_{\mathrm{j}}\right)$, and $\forall \mathrm{a} \leq \mathrm{k} \leq \mathrm{j}-1: \mathrm{e}_{\mathrm{i}}\left(\mathrm{O}_{\mathrm{a}}\right) \| \mathrm{e}_{\mathrm{i}}\left(\mathrm{O}_{\mathrm{j}}\right)$, then we can directly obtain $\mathrm{O}_{\mathrm{j}}$ by applying the list of exclusion transformation function (LET) [21], thus, $\mathrm{O}_{\mathrm{j}}=\operatorname{LET}\left(\mathrm{e}_{\mathrm{i}}\left(\mathrm{O}_{\mathrm{j}}\right), \mathrm{HB}_{\mathrm{i}}^{\mathrm{t}}[\mathrm{a}, \mathrm{j}-1]^{-1}\right)$.

The complicated case is that there is a mixture of independent and dependent operations in the range of $\mathrm{HB}_{\mathrm{i}}{ }^{\mathrm{t}}[\mathrm{a}, \mathrm{j}-1]$. Let $\mathrm{EOL}=\left[\mathrm{EO}_{\mathrm{b} 1}, \mathrm{EO}_{\mathrm{b} 2}, \ldots, \mathrm{EO}_{\mathrm{br}}\right]$ be the list of operations in the range of $\mathrm{HB}_{\mathrm{i}}^{\mathrm{t}}[\mathrm{a}+1, \mathrm{j}-1]$, which are causally preceding $\mathrm{e}_{\mathrm{i}}\left(\mathrm{O}_{\mathrm{j}}\right) . \mathrm{EOL}^{\prime}=\left[\mathrm{EO}_{\mathrm{b} 1}^{\prime}, \mathrm{EO}_{\mathrm{b} 2}^{\prime}, \ldots, \mathrm{EO}_{\mathrm{br}}^{\prime}\right]$, $\mathrm{EO}_{\mathrm{bi}}^{\prime}$ is the original form of operation $\mathrm{EO}_{\mathrm{bi}}$.

For the first operation in EOL, $\mathrm{EO}_{\mathrm{b} 1}^{\prime}=\operatorname{LET}\left(\mathrm{EO}_{\mathrm{b} 1}\right.$, $\left.\mathrm{HB}_{\mathrm{i}}^{\mathrm{t}}[\mathrm{a}, \mathrm{b} 1-1]^{-1}\right)$. For the second operation in EOL, $\mathrm{O}_{\mathrm{b} 1}$ is determined by two step as follows, in which IT is the inclusion transformation function. IT is proposed in [21].

(1) $\mathrm{TO}=\operatorname{LET}\left(\mathrm{EO}_{\mathrm{b} 2}, \mathrm{HB}_{\mathrm{i}}^{\mathrm{t}}\left[\mathrm{a}, \mathrm{b}_{2-1}\right]^{-1}\right)$;

(2) $\mathrm{EO}_{\mathrm{b} 2}^{\prime}=\mathrm{IT}\left(\mathrm{TO}, \mathrm{EO}_{\mathrm{b} 1}^{\prime}\right)$. 
Generally, for the ith operation in EOL, $(2 \leq \mathrm{i} \leq \mathrm{r})$, the following two step is applied to obtain the corresponding form of operation in EOL,

(1) $\mathrm{TO}=\operatorname{LET}\left(\mathrm{EO}_{\mathrm{bi}}, \mathrm{HB}_{\mathrm{i}}^{\mathrm{t}}\left[\mathrm{a}, \mathrm{b}_{\mathrm{i}-1}\right]^{-1}\right)$;

(2) $\mathrm{EO}_{\mathrm{bi}}^{\prime}=\mathrm{IT}\left(\mathrm{TO},\left[\mathrm{EO}_{\mathrm{b} 1}^{\prime}, \mathrm{EO}_{\mathrm{b} 2}^{\prime}, \ldots, \mathrm{EO}_{\mathrm{bi}-1}^{\prime}\right]\right.$.

If the operation list EOL' is obtained, $\mathrm{O}_{\mathrm{j}}$ can be easily get by the following two steps,

(1) $\mathrm{TO}=\operatorname{LET}\left(\mathrm{EO}_{\mathrm{bi}}, \mathrm{HB}_{\mathrm{i}}^{\mathrm{t}}[\mathrm{a}, \mathrm{j}-1]^{-1}\right)$;

(2) $\mathrm{O}_{\mathrm{j}}=\mathrm{IT}\left(\mathrm{TO}, \mathrm{EOL}^{\prime}\right)$.

Algorithm 4. The Generic Operation Revise Transform algorithm, (GORT).

Given the history buffer of $s_{i}$ at time $t \mathrm{HB}_{\mathrm{i}}{ }^{\mathrm{t}}=\left[\mathrm{e}_{\mathrm{i}}\left(\mathrm{O}_{1}\right)\right.$, $\left.\mathrm{e}_{\mathrm{i}}\left(\mathrm{O}_{2}\right), \ldots, \mathrm{e}_{\mathrm{i}}\left(\mathrm{O}_{\mathrm{k}}\right)\right]$, and an operation $\mathrm{e}_{\mathrm{i}}\left(\mathrm{O}_{\mathrm{j}}\right)$ in $\mathrm{HB}_{\mathrm{i}}{ }_{\mathrm{i}}$, the original form of $\mathrm{O}_{\mathrm{j}}$ is obtained as follows,

Scan $\mathrm{HB}_{\mathrm{i}}{ }_{\mathrm{i}}$ from left to right to find the oldest operation $\mathrm{HB}_{\mathrm{i}}^{\mathrm{t}}[\mathrm{a}]$ that independent to $\mathrm{e}_{\mathrm{i}}\left(\mathrm{O}_{\mathrm{j}}\right)$;

if no such operation is found then return $\mathrm{O}_{\mathrm{j}} \leftarrow \mathrm{e}_{\mathrm{i}}\left(\mathrm{O}_{\mathrm{j}}\right)$;

Scan $\mathrm{HB}_{\mathrm{i}}^{\mathrm{t}}[\mathrm{a}, \mathrm{j}-1]$ to find all operations that are causally preceding $\mathrm{e}_{\mathrm{i}}\left(\mathrm{O}_{\mathrm{j}}\right)$.

if no such operation is found

then return $\mathrm{O}_{\mathrm{j}} \leftarrow \operatorname{LET}\left(\mathrm{e}_{\mathrm{i}}\left(\mathrm{O}_{\mathrm{j}}\right), \mathrm{HB}_{\mathrm{i}}^{\mathrm{t}}[\mathrm{a}, \mathrm{j}-1]^{-1}\right)$;

$\mathrm{EO}_{\mathrm{b} 1}^{\prime} \leftarrow \operatorname{LET}\left(\mathrm{EO}_{\mathrm{b} 1}, \mathrm{HB}_{\mathrm{i}}^{\mathrm{t}}[\mathrm{a}, \mathrm{b} 1-1]^{-1}\right)$;

for $(2 \leq \mathrm{i} \leq \mathrm{r})$ do

$\mathrm{TO} \leftarrow \operatorname{LET}\left(\mathrm{EO}_{\mathrm{bi}}, \mathrm{HB}_{\mathrm{i}}^{\mathrm{t}}\left[\mathrm{a}, \mathrm{b}_{\mathrm{i}-1}\right]^{-1}\right) ;$

$\mathrm{EO}_{\mathrm{bi}}^{\prime} \leftarrow \mathrm{IT}\left(\mathrm{TO},\left[\mathrm{EO}_{\mathrm{b} 1}^{\prime}, \mathrm{EO}_{\mathrm{b} 2}^{\prime}, \ldots, \mathrm{EO}_{\mathrm{bi}-1}^{\prime}\right]\right)$;

end for;

$\mathrm{TO} \leftarrow \operatorname{LET}\left(\mathrm{EO}_{\mathrm{bi}}, \mathrm{HB}_{\mathrm{i}}^{\mathrm{t}}[\mathrm{a}, \mathrm{j}-1]^{-1}\right) ;$

return $\mathrm{O}_{\mathrm{j}} \leftarrow \mathrm{IT}\left(\mathrm{TO}, \mathrm{EOL}^{\prime}\right)$;

end algorithm 4.

After each site $s_{j}$ executes the algorithm 3, all lost operations in $s_{i}$ will be executed again at $s_{i}$, and the effect of their execution is remained unchanged. This can be proved in theorem 4.

Assumption 1. There is at least one site $s_{j}$ that, before time $\mathrm{at}_{\mathrm{j}}(\mathrm{r})$, has executed all operations generated at the failed $\mathrm{s}_{\mathrm{i}}$ between time $\sigma$ and $\theta$, thus, $\exists 1 \leq \mathrm{j} \leq \mathrm{n}, \mathrm{j} \neq \mathrm{i}$, t $<$ $\mathrm{at}_{\mathrm{j}}(\mathrm{r}): \forall \mathrm{O}: \sigma<\mathrm{gt}_{\mathrm{i}}(\mathrm{O})<\theta \rightarrow \mathrm{e}_{\mathrm{j}}(\mathrm{O}) \in \mathrm{HB}_{\mathrm{j}}^{\mathrm{t}}$.

Assumption 1 is very essential, for if no site executed all lost operations when recovery message arrives, then some lost operations will never be executed at $s_{i}$ again. Thus, the consistency of the recovery can not be guaranteed.

Theorem 4. Our recovery algorithm generates a consistent recovery.

Proof. Assume that $\mathrm{y}_{\mathrm{i}}^{\mathrm{j}, \sigma}=\mathrm{e}_{\mathrm{i}}\left(\mathrm{O}_{\mathrm{k}}\right)$. For site $\mathrm{s}_{\mathrm{j}}(1 \leq \mathrm{j} \leq \mathrm{n}$, and $\mathrm{j} \neq \mathrm{i}), \mathrm{y}_{\mathrm{j}}^{\mathrm{j}, \delta}=\mathrm{e}_{\mathrm{j}}\left(\mathrm{LO}_{\mathrm{j}}\right)$ is the latest operation, where $\delta=\mathrm{at}_{\mathrm{j}}(\mathrm{r})$ is the arrival time of recovery message $r$ from $s_{i}$ to $s_{j}$. At time $t_{j}=a t_{i}\left(L_{j}\right), e_{i}\left(L_{j}\right) \in H_{B}{ }_{i}^{t j}$ (def. 5). Since recovery algorithm resends operations, which satisfy $s(O)=j$ and $\mathrm{O} \rightarrow \mathrm{y}_{\mathrm{i}}^{\mathrm{j}, \delta}$, to $\mathrm{s}_{\mathrm{i}} ; \mathrm{y}_{\mathrm{i}}^{\mathrm{j}, \sigma} \rightarrow \mathrm{y}_{\mathrm{j}}^{\mathrm{j}, \delta}$, hence, $\mathrm{y}_{\mathrm{j}}^{\mathrm{j}, \delta}$ is send to $\mathrm{s}_{\mathrm{i}}$ again. Because $\forall \mathrm{e}_{\mathrm{j}}(\mathrm{O}) \in \mathrm{HB}_{\mathrm{j}}{ }_{\mathrm{j}}: \mathrm{s}(\mathrm{O})=\mathrm{j} \rightarrow\left(\mathrm{O} \rightarrow \mathrm{y}_{\mathrm{j}}^{\mathrm{j}}, \delta\right)$ (def. 8), we prove that at time $\mathrm{t}_{\mathrm{j}}, \forall \mathrm{O}: \mathrm{gt}_{\mathrm{j}}\left(\mathrm{O}_{\mathrm{k}}\right)<\mathrm{gt}_{\mathrm{j}}(\mathrm{O})<\mathrm{at}_{\mathrm{j}}(\mathrm{r}) \rightarrow$ $\mathrm{e}_{\mathrm{i}}(\mathrm{O}) \in \mathrm{HB}_{\mathrm{i}}{ }^{\mathrm{tj}}$, (property of causality preservation). Thus, we obtain $\mathrm{t}_{\alpha}=$
$\operatorname{MAX}_{1 \leq j \leq n, j \neq i}\left(t_{j}\right)=\operatorname{MAX}_{1 \leq j \leq n, j \neq i}\left(a t_{i}\left(L O_{j}\right)\right)$

At time $\mathrm{t}_{\alpha}$, we have $\forall \mathrm{O}, 1 \leq \mathrm{j} \leq \mathrm{n}, \mathrm{j} \neq \mathrm{i}: \mathrm{gt}_{\mathrm{j}}\left(\mathrm{O}_{\mathrm{k}}\right)<$ $\mathrm{gt}_{\mathrm{j}}(\mathrm{O})<\mathrm{at}_{\mathrm{j}}(\mathrm{r}) \rightarrow \mathrm{e}_{\mathrm{i}}(\mathrm{O}) \in \mathrm{HB}_{\mathrm{i}}^{\mathrm{t} \alpha}$. (1)

According to assumption 1 , let $\mathrm{s}_{\mathrm{k}}$ be the site that has executed all operations generated at $\mathrm{s}_{\mathrm{i}}$ between $\sigma$ and $\theta$, thus, $\exists \mathrm{t}<\delta$ : $\forall \mathrm{O}: \sigma<\mathrm{gt}_{\mathrm{i}}(\mathrm{O})<\theta \rightarrow \mathrm{e}_{\mathrm{k}}(\mathrm{O}) \in \mathrm{HB}_{\mathrm{k}}{ }^{\mathrm{t}}$. So, we obtain $\forall \mathrm{O}: \sigma<\mathrm{gt}_{\mathrm{i}}(\mathrm{O})<\theta \rightarrow \mathrm{e}_{\mathrm{k}}(\mathrm{O}) \in \mathrm{HB}_{\mathrm{k}}{ }^{\delta}(2)$

Let $\delta$ be the arrival time of recovery message from $\mathrm{s}_{\mathrm{i}}$ to $\mathrm{s}_{\mathrm{k}}, \delta=\mathrm{at}_{\mathrm{k}}(\mathrm{r})$, and $\mathrm{y}_{\mathrm{k}}{ }^{\mathrm{i}, \delta}=\mathrm{e}_{\mathrm{k}}\left(\mathrm{LO}_{\mathrm{k}}{ }^{\prime}\right)$ is the latest operation from $s_{\mathrm{i}}$ in $\mathrm{HB}_{\mathrm{k}}{ }^{\delta}$. As described in our algorithm, these operations are sent back to $\mathrm{s}_{\mathrm{i}}$ again, we have $\exists \mathrm{t}_{\beta}=$ $\mathrm{at}_{\mathrm{i}}\left(\mathrm{LO}_{\mathrm{k}}{ }^{\prime}\right)>\delta: \mathrm{e}_{\mathrm{i}}\left(\mathrm{LO}_{\mathrm{k}}{ }^{\prime}\right) \in \mathrm{HB}_{\mathrm{i}}{ }^{\mathrm{t} \beta}$. Since $\forall \mathrm{e}_{\mathrm{k}}(\mathrm{O}) \in \mathrm{HB}_{\mathrm{k}}{ }^{\delta}$ : $\mathrm{s}(\mathrm{O})=\mathrm{i} \rightarrow\left(\mathrm{O} \rightarrow \mathrm{LO}_{\mathrm{k}}{ }^{\prime}\right)$, we prove that at time $\mathrm{t}_{\beta}, \forall \mathrm{e}_{\mathrm{k}}(\mathrm{O})$ $\in \mathrm{HB}_{\mathrm{k}}{ }^{\delta}: \mathrm{s}(\mathrm{O})=\mathrm{i} \rightarrow \mathrm{e}_{\mathrm{i}}(\mathrm{O}) \in \mathrm{HB}_{\mathrm{i}}{ }^{\mathrm{t} \beta}$ (3) (based on causality property).

Based on (2) and (3), we prove that at time $\mathrm{t}_{\beta}, \forall \mathrm{O}: \sigma<$ $\mathrm{gt}_{\mathrm{i}}(\mathrm{O})<\theta \rightarrow \mathrm{e}_{\mathrm{i}}(\mathrm{O}) \in \mathrm{HB}_{\mathrm{i}}{ }^{\mathrm{t} \beta}$ (4). According to (1) and (4), we have $\exists \mathrm{t}=\operatorname{MAX}\left(\mathrm{t}_{\alpha}, \mathrm{t}_{\beta}\right)>\gamma: \forall \mathrm{O}:\left(\mathrm{s}(\mathrm{O})=\mathrm{i} \wedge \sigma<\mathrm{gt}_{\mathrm{i}}(\mathrm{O})<\right.$ $\theta) \vee\left(\mathrm{s}(\mathrm{O})=\mathrm{j} \neq \mathrm{i} \wedge \mathrm{gt}_{\mathrm{j}}\left(\mathrm{O}_{\mathrm{k}}\right)<\mathrm{gt}_{\mathrm{j}}(\mathrm{O})<\mathrm{at}_{\mathrm{j}}(\mathrm{r})\right) \rightarrow \mathrm{e}_{\mathrm{i}}(\mathrm{O}) \in$ $\mathrm{HB}_{\mathrm{t}}{ }^{\mathrm{i}}$, where $\mathrm{y}_{\mathrm{i}}{ }^{\mathrm{j}, \sigma}=\mathrm{e}_{\mathrm{i}}\left(\mathrm{O}_{\mathrm{k}}\right)$. Thus, the recovery is consistent.

\section{Performance Analysis}

This section evaluates the performance of our new approach of recovery support for collaborative editing systems. We assume that when a site leaves the collaborative editing system successfully, it had created $\mathrm{m}$ checkpoints. The expected interval time between a site join and leave the system reflects the performance of the system. Under the same workload, the shorter the interval time, the better performance the system. We investigate the factors that make significant impact on this interval time.

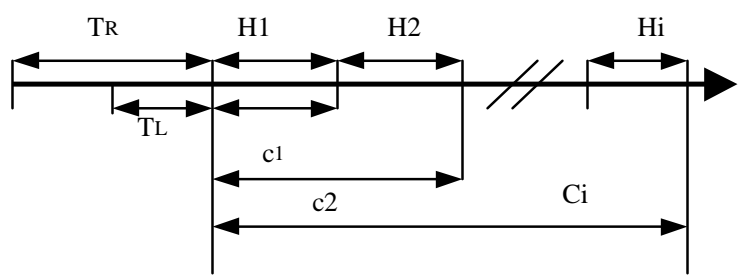

Figure 2. Definition for $\mathrm{ci}, \mathrm{Hi}, \mathrm{TL}$ and TR

As displayed in figure $2, \mathrm{P}_{\mathrm{i}}(2 \leq \mathrm{i} \leq \mathrm{m})$ represents the execution time on site, it is the nominal measured in CPU cycles between (i-1)th and ith checkpoints, $\mathrm{P}_{1}$ denotes the interval between the beginning of the site and its first checkpoint without any failures. The sum of the execution time is defined as $P=\sum_{i=1}^{m} P_{i}$.

Let $c_{i}(1 \leq \mathrm{i} \leq \mathrm{m})$ be the execution time from the 
beginning of the site to the ith checkpoint in presence of the site or link failures. Let $C_{i}$ be the expected value of $c_{i}$, $C_{i}=E\left(c_{i}\right)$, thus, the expected interval time of a site between join and leave the collaborative editing system is $C_{m}=E\left(c_{m}\right)$.

The site and the Internet link failures can be recovered by either loading LDS or remote document state. Let $p$ and $q$ be the probability of recovering the site by using our new LDS approach and the traditional RDS approach, respectively, it is clear that $p+q=1$. Let $\mathrm{T}_{\mathrm{L}}$ and $T_{R}$ denote time overhead for loading LDS and RDS, respectively. $f_{i}(\mathrm{t})(\mathrm{i} \in[2, \mathrm{~m}])$ denotes the probability of a site/link failure in $t$ unit of time from the time of the (i1)th checkpoint. $f_{l}(\mathrm{t})$ is the failure probability from the very beginning. We have,

$$
c_{l}=\left\{\begin{array}{cc}
P_{l} & \text { with probability } 1-f_{l}\left(P_{l}\right) \\
P_{l}+T_{L}+c_{l} & \text { with probability } p \times f_{l}\left(P_{l}\right) \\
P_{l}+T_{R}+c_{l} & \text { with probability } q \times f_{l}\left(P_{l}\right)
\end{array}\right.
$$

Let $H_{i}$ be the time interval between (i-1)th and ith checkpoint. Thus, for $2 \leq \mathrm{i} \leq \mathrm{m}$,

$$
\begin{aligned}
& c_{i}=c_{i-1}+H_{i}+T_{C} \\
& H_{1}=c_{l} \\
& H_{i}=\left\{\begin{array}{cl}
P_{i} & \text { with probability } 1-f_{i}\left(P_{i}\right) \\
P_{i}+T_{L}+c_{i} & \text { with probability } p \times f_{i}\left(P_{i}\right) \\
P_{i}+T_{R}+c_{i} & \text { with probability } q \times f_{i}\left(P_{i}\right)
\end{array}\right.
\end{aligned}
$$

$C_{i}$ is derived from equations (5) as follows, where $2 \leq$ $\mathrm{i} \leq \mathrm{m}$,

$$
C_{i}=\frac{C_{i-1}+P_{i}+\left(p T_{L}+q T_{R}\right) f_{i}\left(P_{i}\right)}{1-f_{i}\left(P_{i}\right)}
$$

$C_{m}$ represents the expected interval time of the site between join and leave the system, it is obtained by applying the above equation $\mathrm{m}-1$ times,

$C_{m}=$

$$
\sum_{j=1}^{m} \prod_{i=j}^{m}\left\{\left[P_{j}+\left(p T_{L}+q T_{R}\right) f_{j}\left(P_{j}\right)\right] /\left[1-f_{i}\left(P_{i}\right)\right]\right\}
$$

The value of $C_{m}$ reflects the performance of the system. Hence, in order to enhance the performance, $C_{m}$ can be minimized by determining the proper checkpointing frequency. The value of $\mathrm{m}$ that minimizes the equation (7) is an optimal one.

Let $C^{L}(P, k)$ denote the execution time of the site in the presence of up to $\mathrm{k}$ recovering by loading $\mathrm{LDS}$, let $p_{i}^{S}$ and $p_{i}{ }^{U}$ be the probability of the ith LDS approach becoming successful and unsuccessful, respectively, where $p_{i}^{S}+p_{i}^{U}=1 . C^{L}(P, k)$ is given as below,

$$
C^{L}(P, k)=\left(P+T_{L}\right) p_{1}^{S}+2\left(P+T_{L}\right) p_{1}^{U} p_{2}^{S}+\ldots+k\left(P+T_{L}\right)
$$$$
\prod_{i=1}^{k-1} p_{i}^{U} p_{k}^{S}+\left[k\left(P+T_{L}\right)+\frac{P+T_{R}}{1-f_{1}(P)}\right] \prod_{i=1}^{k} p_{i}^{U}
$$$$
=\sum_{j=1}^{k-1}\left[j\left(P+T_{L}\right)\right] \prod_{i=1}^{j-1} p_{i}^{U} p_{j}^{S}+k\left(P+T_{L}\right) \prod_{i=1}^{k-1} p_{i}^{U}
$$

$$
+\left[\frac{P+T_{R}}{1-f_{1}(P)}\right] \prod_{i=1}^{k-1} p_{i}^{U}
$$

$p_{i}^{S}$ and $p_{i}^{U}$ are not known until (i-1)th unsuccessful LDS recovery occurs. We derive the approximate probability for $p_{i}^{S}$ and $p_{i}{ }^{U}$. It is clear that with the increase number of unsuccessful LDS recoveries, the probability of permanent rises, thus,

$$
p_{1}{ }^{U}<p_{2}{ }^{U}<\ldots<p_{k}{ }^{S} \text { and } p_{I}{ }^{S}>p_{2}{ }^{S}>\ldots>p_{k}{ }^{S}
$$

We assume that $p_{i}^{S} / p_{i-1}^{S}=w_{i}<1$, and for the simplicity, it is assumed that $w_{1}=w_{2}=\ldots=w_{k}=w$, and $p_{1}^{S}=p$. Equation 9 is derived from equation 8 as follows,

$$
\begin{aligned}
& C^{L}(P, k)=\sum_{j=1}^{k-1}\left[j\left(P+T_{L}\right)\right] \prod_{i=1}^{j-1}\left(1-p w^{i-1}\right) \\
& +k\left(P+T_{L}\right) \prod_{i=1}^{k-1}\left(1-p w^{i-1}\right)+ \\
& {\left[\left(P+T_{R}\right) /\left(1-f_{1}(P)\right] \prod_{i=1}^{k}\left(1-p w^{i-1}\right)\right.}
\end{aligned}
$$

The time overhead of LDS recovery is determined by $\mathrm{P}$ and the arrival rate of operations $\lambda$. Suppose the operation arrival rate is constant, hence, with the increase of $\mathrm{P}$, the probability of successful LDS recovery decreased, and the time overhead of the unsuccessful LDS also increases. On the other hand, the time overhead of RDS recovery is decided by the data volume associated with the context of the document. For the simplicity, we assume that the cost of the RDS recovery remains constant, and it is modelled as follows,

$$
C^{R}(P)=\frac{P+T_{R}}{1-f_{1}(P)}
$$

LDS recovery is an efficient method to recover the temporary failures in site and links. It continues working until the permanent failure occurs (checkpoint stored on local storage is missing) or the time overhead of LDS recovery is larger than RDS recovery. Thus, given value $\mathrm{P}, \quad C^{L}(P, k)$ can be determined by $\mathrm{k}$, which must satisfies $C^{L}(P, k)<C^{R}(P)$.

The table 1 describes the relation between $\mathrm{k}$ and $C^{L}(P, k) . \mathrm{P}$ is set to 100,200 and 300 , respectively. $\mathrm{C}^{\mathrm{L}}$ first decreases with the increase of $\mathrm{k}$, and when $\mathrm{k}=12, \mathrm{C}^{\mathrm{L}}$ is the minimized. After $\mathrm{k}=12, \mathrm{CL}$ rises with the increase of $\mathrm{k}$. In this case, 12 is the optimal value for $\mathrm{k}$.

Table 1. $T_{L}=20, T_{R}=40, w=0.8, p=0.8, f_{1}(P)=0.1$

\begin{tabular}{|l|l|l|l|l|l|l|}
\hline $\mathrm{k}$ & 2 & 4 & 6 & 8 & 10 & 12 \\
\hline $\mathrm{P}=100$ & 179.24 & 177.61 & 170.46 & 167.69 & 166.68 & 166.14 \\
\hline $\mathrm{P}=200$ & 327.2 & 325.22 & 312.32 & 307.31 & 305.47 & 305.00 \\
\hline $\mathrm{P}=300$ & 475.2 & 473.85 & 454.18 & 446.92 & 444.28 & 443.59 \\
\hline $\mathrm{K}$ & 14 & 16 & 18 & 30 & 50 & 100 \\
\hline $\mathrm{P}=100$ & 166.53 & 166.86 & 167.36 & 171.56 & 179.56 & 199.77 \\
\hline $\mathrm{P}=200$ & 305.22 & 305.85 & 306.76 & 314.56 & 329.14 & 366.18 \\
\hline $\mathrm{P}=300$ & 443.92 & 444.85 & 446.15 & 457.36 & 478.71 & 532.60 \\
\hline
\end{tabular}

To study the impact of the probability of the first 
successful LDS recovery on $C^{L}(P, k)$, we fixed $\mathrm{T}_{\mathrm{L}}, \mathrm{T}_{\mathrm{R}}$, $\mathrm{w}$, and $\mathrm{f}_{1}(\mathrm{P})$, and increased $\mathrm{k}$ from 10 to 30 with increments of 10 . Table. 2 shows the execution time of the site in the presence of up to $\mathrm{k}$ LDS recovery as a function of $p$. The higher the probability $p$ is, the less execution time of the site in the presence of up to $k$ LDS recovery is. It suggests that a higher probability of the first successful LDS recovery result in a better performance.

Table 2. $P=100, T_{L}=20, T_{R}=40, w=0.8, f_{1}(P)=0.1$

\begin{tabular}{|l|l|l|l|l|l|l|}
\hline $\mathrm{p}$ & 0.65 & 0.70 & 0.75 & 0.8 & 0.85 & 0.9 \\
\hline $\mathrm{K}=10$ & 208.48 & 192.86 & 179.17 & 166.68 & 154.84 & 143.26 \\
\hline $\mathrm{K}=20$ & 217.40 & 197.87 & 181.80 & 167.94 & 155.37 & 143.41 \\
\hline $\mathrm{K}=30$ & 234.33 & 208.49 & 188.18 & 171.56 & 157.25 & 144.29 \\
\hline
\end{tabular}

Table 3 illustrates the relation between $w$ and

$C^{L}(P, k) . T_{L}, T_{R}, p$, and $f_{l}(P)$ are fixed, and $\mathrm{k}$ is set to 10, 20 and 30, respectively. Like the effect of p on $C^{L}$, as the value of $\mathrm{w}$ rises, the execution time of the failed site in the presence of up to $\mathrm{k}$ LDS recovery decreases. This is because with the increase of value $w$, the probability of ith unsuccessful LDS recovery decreases, and as $p_{i}^{U}$ drops, $C^{L}$ decreases. This suggests that if we could increase the probability of the successful LDS recovery, the performance of the system is enhanced.

Table 3. $P=100, T_{L}=20, T_{R}=40, p=0.8, f_{1}(P)=0.1$

\begin{tabular}{|l|l|l|l|l|l|l|}
\hline $\mathrm{W}$ & 0.65 & 0.70 & 0.75 & 0.8 & 0.85 & 0.9 \\
\hline $\mathrm{K}=10$ & 195.14 & 181.91 & 172.25 & 166.68 & 164.94 & 165.98 \\
\hline $\mathrm{K}=20$ & 231.97 & 202.70 & 180.73 & 167.94 & 164.01 & 165.48 \\
\hline $\mathrm{K}=30$ & 270.74 & 226.14 & 192.10 & 171.56 & 164.40 & 165.44 \\
\hline
\end{tabular}

\section{Related Work}

Collaborative editing has been studied deeply. Collaborative editing systems can be classified into two categories: Real-time and non real-time [15]. Non realtime collaborative editing systems have shared documents that can be accessed and locked separately. A shared repository, such as distributed file system, serves as the infrastructure for many non real-time collaborative systems [10][11][26]. In real-time collaborative editing systems, multiple users are allowed to concurrently edit any part of the document simultaneously. REDUCE[23] and SASSE[2] are good examples for real-time collaborative systems.

Most the research works in real-time collaborative editing systems focus on user intention preservation [8], consistency maintenance [20] [21], group undo [18], and group awareness [6][24][25], fault-tolerance and reliability issues, however, have not been studied deeply. If the real-time collaborative editing system is to be efficiently used over a wide area network, the faulttolerant issues must be take into account, for the reason that wide area network are usually unreliable [16]. If group communication subsystems are designed and implemented properly, they can provide an infrastructure for building distributed and reliable services on top of their message broadcasting and membership services [1][9]. The drawback of these systems is that they do not directly manage groups' shared application state and transfers groups' state to new sites. Paper [16] provides the practical fault-tolerant services for collaborative system. Since these systems are designed for general purpose, they do not study the concurrency control issues.

Paper [7] presents the requirements for the collaborative editor, and proposes a model that has faulttolerant feature. This technique is also discussed in paper [1]. However, they do not consider the consistency maintenance, which is fully taken into account in our approach. PREP [10] is a collaborative writing system that uses the concept of flexible diff-ing for reporting differences between versions of texts. It is clear that this system supports the fail recovery automatically. The major difference between this approach and our algorithm is that, it is only suitable for non real-time collaborative editing systems, but our algorithm is devised for real-time collaborative editing systems.

\section{Conclusion}

An efficient recovery algorithm is presented to make the real-time collaborative systems more reliable. In our new approach, each site maintains a LDS, which is generated periodically. If a failure occurs in the site or links, the site is able to rejoin the collaborative editing systems by loading the LDS instead of obtaining the state from other sites that may result in a noticeable delay

In our model of performance evaluation, the time overhead of LDS recovery was modelled as a constant. In fact, it was determined by the frequency of taking a checkpoint and the arrival rate of operations. It is not known how these two factors affect the time overhead of LDS recovery. Implications of big differences. Further work needed.

An assumption implied in the model that each site maintains a history buffer with an infinite storage capacity is not practical. However, the purpose of the history buffer is to support the undo/transform-do/transform-redo scheme and the recovery, an operation need not to be kept into the history buffer if is it is no longer involved in these two procedures. Therefor, our continuous work focuses on devising the technique for garbage collection, which overcomes this storage problem.

\section{Acknowledgments}

The authors want to thank David Chen for his insightful suggestions. We also would like to especially thank Peter Hasker for his valuable comments that helped improve the final presentation of this paper. The work reported in this paper was supported in part by an ARC (Australia Research Council) Large Grant (A00000711). 


\section{Reference}

[1] Y. Amir, D. Dolev, S.Kramer, and D. Malki. Transis: A Communication Sub-System for High Availability. Technical Report TR CS91-13, Computer Science Department, Hebrew University, April 1992.

[2] E.E. Beck and V.M.E. Bellotti. Informed Opportunism as Strategy: Supporting Coodination in Distributed Collaborative Writing. In Proceedings of $3^{\text {rd }}$ European Conference on Computer Supported Cooperative Work, Milan, Italy, pp.233-248, 1993.

[3] David Chen and Chengzheng Sun. A distributed algorithm for graphic objects replication in real-time group editors. In Proceedings of the international ACM SIGGROUP conference on Supporting group work, Phoenix, AZ USA, pp.121-1301999.

[4] C.A.Ellis. Coordination Technology, Trends in CSCW, Michel Beaudouin-Lafon (ed.), Wiley, 1997.

[5] P. Godefroid, J.D. Herbsleb, L.J. Jagadeesan, and Du Li. Ensuring Privacy in Presence Awareness Systems: An Automated Verification Approach. In Proceedings of ACM 2000 Conference on Computer Supported Cooperative Work, December, Philadelphia, Pennsylvania, USA, 2000.

[6] H. Higaki, K. Tanaka, and M. Takizawa. Protocol for Pseudo-Active Replication in Wide-Area Networks. In Proceeding of the 2nd International Workshop on NetworkBased Information Systems (NBIS), pp.678-682,1999.

[7] M. Koch. Design Issues and Model for a Distributed Multiuser Editor. Computer Supported Cooperative Work, 3(3-4), pp.359-378, 1995.

[8] Du Li, Limin Zhou, and Richard R. Muntz. A new paradigm of user intention preservation in realtime collaborative editing systems. In Proceedings of the Seventh International Conference on Parallel and Distributed Systems, Iwate, Japan, July, 2000.

[9] S. Mishra, L.L. Peterson, and R.D. Schlichting. Consul: A Communication Substrate for Fault-Tolerant Distributed Program. Distributed Systems Engineering Journal, 1(2), pp.87-103, Dec. 1993.

[10] C.M. Neuwirth, R. Chandhok, D.S.Kaufer, P.Erion, J.H. Morris, and D.Miller. Flexible Diff-ing in a Collaborative Writing System. In Proceedings of $4^{\text {th }}$ International Conference on Computer Supported Cooperative Work, Toronto, CA, pp.147-154, 1992.

[11] F. Pacull, A. Sandoz, and A. Schiper. Duplex: A Distributed Collaborative Editing Environment in Large Scale. In Proceedings of International Conference on Computer Supported Cooperative Work, Chapel Hill, NC, pp.165-173, October 1994.

[12] A. Prakash, H.S. Shim, and J.H. Lee. Issues and Tradeoffs in CSCW Systems. IEEE Transactions on Data and Knowledge Engineering, Jan.-Feb., 11(1), pp. 213-227, 1999.

[13] Xiao Qin, Z.F. Han, H. Jin, L.P Pang and SL Li, Real-time Fault-tolerant Scheduling in Heterogeneous Distributed Systems, Proceeding of the 2000 International Workshop on Cluster Computing-Technologies, Environments, and Applications (CC-TEA'2000), Las Vegas, Nevada, USA, June, 2000

[14] M. Ressel, D. Nitsche-Ruhland, and R. Gunzenbauser, An intergrating, transformation-oriented approach to concurrency control and undo in goup editors. In Proceedings of the ACM Conference on ComputerSupported Cooperative Work, pp. 288-297, 1996.

[15] M. A. Sasse and M. J. Handley. Collaborative Writing With Synchronous and Asynchronous Support Environments. In Rada, R. [Ed.]: Groupware and Authoring, Academic Press, pp 205-218, 1996.

[16] H. S. Shim, A. Prakash. Tolerating Client and Communication Failures in Distributed Groupware Systems. In Proceedings of the 17th IEEE Symposium on Reliable Distributed Systems, pp.221-227, West Lafayette, Indiana, USA, 1998.

[17] K. F. Ssu, B. Yao and W. K. Fuchs. An Adaptive Checkpointing Protocol to Bound Recovery Time with Message Logging. In Proceeding of the 18th IEEE Symposium on Reliable Distributed Systems, Lausanne, Switzerland, October, 1999

[18] C. Sun. Undo any operation at any time in group editors. In Proceedings of ACM 2000 Conference on Computer Supported Cooperative Work, December, Philadelphia, Pennsylvania, USA, 2000.

[19] C. Sun and C.A. Ellis. Operational transformation in realtime group editors: Issues, algorithms, and achievements. In Proceedings of ACM Conference on Computer Supported Cooperative Work, Seattle, USA, November 1998.

[20] C. Sun, Y. Yang, Y. Zhang, and D. Chen. Distributed Concurrency Control in Real-time Cooperative Editing Systems. In Proceedings of the Asian Computing Science Conference, Lecture Notes in Computer Science, Vol. 1179. Springer-Verlag, 84-95, Dec. 1996.

[21] C. Sun, X. Jia, Y. Zhang, Y. Yang, and D. Chen. Achieiving convergence, causality-preservation, and intention preservation in real-time cooperative editing systems. ACM Transactions on Computer-Human Interaction, 5(1):63-108, March 1998.

[22] J. B. Weissman. Fault Tolerant Wide-Area Parallel Computing. Fault-tolerant Wide-Area Computing. Workshop on Fault-Tolerant Parallel and Distributed Systems FTPDS '00, April 2000.

[23] Y. Yang, C Sun, Y.C. Zhang, and X.H. Jia. Real-Time Cooperative Editing on the Internet. IEEE Internet Computing, pp.18-25, May/June 2000.

[24] Y. Yokota, H. Tarumi, and Y. Kambayashi. Extended Awareness Support for Cooperative Work in NonWYSIWIS Condition. In Proceedings of International Computer Science Conference, Springer-Verlag, 1999.

[25] W. Prinz. NESSIE: An awareness environment for cooperative settings. In Proceedings of the Sixth European conference on Computer Supported Cooperative Work, Kluwer Academic Publishers, pp. 391-410, 1999.

[26] E.J. Whitehead, Jr. and Y.Y. Goland. WebDAV: A network protocol for remote collaborative authoring on the Web. In Proceedings of the Sixth European conference on Computer Supported Cooperative Work, Kluwer Academic Publishers, pp. 291-310, 1999.

[27] J. Trevor, T. Koch, and G. Woetzel. MetaWeb: Bringing synchronous groupware to the World Wide Web. In Proceedings of the fifth European conference on Computer Supported Cooperative Work, Kluwer Academic Publishers, pp. 65-80, 1997. 